\title{
Building a Successful Reading Culture through the School Library: A Case Study of a Singapore Secondary School
}

\author{
Loh Chin Ee, Mary Ellis, Agnes Alcantara Paculdar, and Wan Zhong Hao \\ National Institute of Education, Singapore \\ Ng Yuiyun \\ Commonwealth Secondary School, Singapore
}

\begin{abstract}
Much research has documented the strong correlation between independent reading and academic achievement, and the school library can serve a crucial role in encouraging reading. Drawing from one case study out of a larger dataset of six schools, this paper details how one school transformed its school library and made it a central place for reading within the school. Data collected provided evidence of the kinds of strategies, programmes and design that works to encourage reading. Schoolwide reading surveys, interviews with principals, teachers and Library coordinators at each school and interviews with students gave an understanding of the culture of reading and library use within the school. Qualitative library observations, timed counts, narratives and time-lapse photographs of library space contribute to our understanding of how particular spaces within the library was used for reading or not. Factors for building a reading culture include: (1) Designing conducive spaces for reading, (2) Curating the selection for readers, (3) Creating programmes to excite readers, (4) Designing spaces for reading, and (5) Building an ecology for reading.
\end{abstract}

\section{Keywords: School Libraries, Reading Culture, Secondary Schools, Singapore, Library Design}

\section{INTRODUCTION}

There is increasing concern worldwide with students' literacy levels, with many nations leaning towards more instrumental approaches towards reading instruction, in the hope that systematic standardized instruction can improve the reading scores of students. The anxiety about reading springs from the belief that reading is a foundational skill for economic and civic participation, as well as lifelong learning. Within Singapore, the National Reading Movement launched in 2015 aims to encourage reading as a national habit and to build a community of readers within the nation. This paper examines how school libraries can be effective agents of change for transforming schools into reading schools by drawing selectively on a single case study from a large-scale mixed-methods study of six secondary school libraries in Singapore to illustrate how school library can be central to building a reading culture.

\section{School Libraries and Reading}

\section{THEORETICAL FRAMEWORK}

Much research has demonstrated the correlation between leisure reading (otherwise termed as free, independent, voluntary or extensive reading) and reading achievement (Anderson et al., 1988; Kirsch et al., 2002; Samuels and Wu, 2001; Krashen, 2004). Besides gain in reading comprehension, vocabulary growth, spelling ability, grammatical usage and writing style, students who read well are able to access more texts and knowledge through wide and varied reading (Cunningham and Stanovich, 1998). This "information capital" (Neuman and Celano, 2012) that students acquire through extensive and wide reading leads to acquisition of more knowledge, including those required for doing well in academic subjects. Good readers thus gain more by reading more whereas weak readers who have to exert more effort at decoding are less likely to be motivated to engaged in further reading required for improved 
comprehension and knowledge acquisition (Allington, 1984). This leads to a "Matthew effect" (Stanovich, 1986) where skilled readers' knowledge acquisition is accelerated through reading while weaker readers lag behind as a result of their lack of reading proficiency, practice and motivation.

As such, reading engagement is an important component, particularly for motivating poor readers. Beyond academic grades, engaged reading is a precursor to independent learning as skilled readers learn more about language and the world through their reading (Cunningham and Stanovich 1998, Krashen 2004). Students who are intrinsically motivated are more likely to read (Wigfield and Guthrie, 1997), and students are motivated to read when they have access to good quality and diversity of reading materials (Ivey and Broaddus, 2001). In this model of reading engagement, independent reading is a nonnegotiable element of a school's reading programme (Gambrell, 2013), and the push towards engaged reading must be a whole school effort (Francois, 2015).

School libraries can play a central role in cultivating a reading culture (Adkins and Brendler, 2015) and raising academic achievement (Barratt, 2010; Lance, 2002; Todd and Kuhlthau, 2005), though its importance is often underestimated in a climate of budgetary constraints. The International Federation of Library Associations' (IFLA) School Library Manifesto (IFLA School Libraries Section Standing Committee, 2015) explains that a core role of the school library is to develop and sustain "in children the habits and enjoyment of reading and learning, and the use of libraries throughout their lives" (p. 61). This focus on reading for pleasure and reading as a part of learning contributes to the school library's mission to provide "information and ideas that are fundamental to functioning successfully in today's information and knowledge-based society" to equip students "with life-long learning skills" and develop "the imagination" to enable students "to live as responsible citizens" (p. 16). School librarians can help curate the book collection and help students to select books they are interested in such as popular Young adult literature, comics and magazines (Constantino, 2008; Getrost and Lance, 2014; Ujiie and Krashen, 1996) or function as reading specialists helping weaker readers with their reading (Parrott and Keith, 2015). Programmes such as book clubs and summer reading programmes can be organised to encourage students to read (Lu and Gordon, 2007).

The school library may be particularly important in helping less proficient readers from lower socioeconomic status families read. In the preliminary findings from the survey portion of our survey, we have found that while there is a significant correlation between number of books owned by students and their visits to the public library, there is no correlation between number of books owned and visits to the school library. In fact, low-performing students from lower income homes interviewed shared that they preferred to read in school if the environment is conducive. Thus, it is important that schools harness the school library as a central place for building a reading culture.

\section{School Library Design}

Other than rethinking the book collection and reading programmes as ways to encourage reading behaviours, re-designing and refreshing the library space is another way to encourage students to visit the school library. Design and organization of space can influence social relations within space (Lefebvre, 1991), and how students feel about a particular space contributes to their desire to visit the space and to engage in particular learning behaviours. Grosvenor and Burke (2008), in their historical study of school buildings in the United Kingdom, reflect that school furniture can be seen "to reflect pervasive notions of pedagogy" and "promote ideas and theories about the relationship between pupil and teacher and between body and mind in learning" (p. 10).

Barker's (1968) theory of behaviour settings explain how "units of environment" influence human behavior and can be applied to our understanding of how educational spaces can be organised to improve pedagogical outcomes. The physical environment can provide cues to shape social behavior within particular spaces, and the spaces can be deliberately and thoughtfully assembled to encourage preferred learning behaviours (Cleveland, 2017). Thus, if reading is to be a priority in school libraries, spaces should be designed and furniture organized to encourage different forms of reading within the space. Furthermore, it should be integrated into the reading culture within the school. 
Bland et al. (2013) suggest that understanding the patterns of participation that particular learning spaces can provide can help educators maximize their use of library space. From their study of seven recently renovated libraries in Queensland, Australia they developed a typology to better understand how library spaces were used in schools.

1. Expanded spaces embraced experiences that had also occurred within old library space that were extended to become richer or more diverse in the new spaces;

2. Enabled spaces provided for experiences of new practices that were made possible by new library spaces;

3. Informal spaces allowed for new experiences for students that occurred outside of the formal curriculum; and

4. Extended spaces enabled learners to be positioned as members of a community, and to engage with the community within the new library spaces (p. 132).

The typology helps with the analysis of how the library space can be utilized for different learning outcomes. It provides a way of evaluating the effectiveness of space usage for pedagogic purposes. In our case study school, the traditional library space is thoughtfully redesigned to extend the role of the library as a reading space. We also see how new ways of reading were encouraged through the redesign, and how the culture of reading in this school encouraged students to colonize (Shilling and Cousins, 1990) multiuse and informal spaces for reading. Within the newly redesigned library, policies and programmes were implemented to support the school's vision of their students as lifelong readers who read for enjoyment and learning.

\section{METHODS}

The case study in this paper detailed in this paper draws from a large-scaled study of six secondary school libraries in Singapore. The case study school, Commonwealth Secondary School, provides an interesting study of how a school library transformed its under-utilized school library into one which is highly popular with and utilized frequently by the students. More importantly, the library was designed with the specific purpose of encouraging reading and we were able to document the effectiveness of the various design strategies between September 2016 to May 2017 through survey, observation and interview data. Visual data such as photographic stills and time-lapse photography allowed us to analyze how space was utilized by the students.

\section{The Context}

The impetus to renovate the school library arose from the vision of the school leader to build a place where students can be encouraged to read in a self-directed way. Guided therefore by this goal, the Head of Department of English was appointed the Library Coordinator and tasked, with four other teachers, to use Design Thinking as the process for working towards a user-centric library that would encourage independent reading, study and collaboration. Design Thinking is a process created by IDEO (2017) that focuses on a structured design process to generate ideas to resolve identified issues. The five steps of Design Thinking involve Discovery, Interpretation, Ideation, Experimentation and Evolution.

After identifying the need to renovate the library space to encourage reading (Discovery), the Library committee members interviewed students and shadowed them to find out more about how student would want to use the library space (Interpretation). Based on their understanding of student needs and research, they generated ideas (Ideation and Experimentation). Key features in the library central to the strategy for building a reading culture include allocating the best location in the library (beside the greenery) for a reading corner, building multi-purpose spaces such as performance steps that can also be used for reading, beanbags for more comfortable reading while lounging, careful curating of books and attractive retail style book displays. Even after the renovation, the Library Team continued to monitor library usage and added features to the library based on their observations and student feedback (Evolution).

The Library Space 
A physical mapping of the school was completed and photographs taken to record how the space was used and how the use of space evolved over time. The layout provided us with a visual of the space and the photographs were used to track the changes over time. They also provide data for discussion alongside the written field notes.

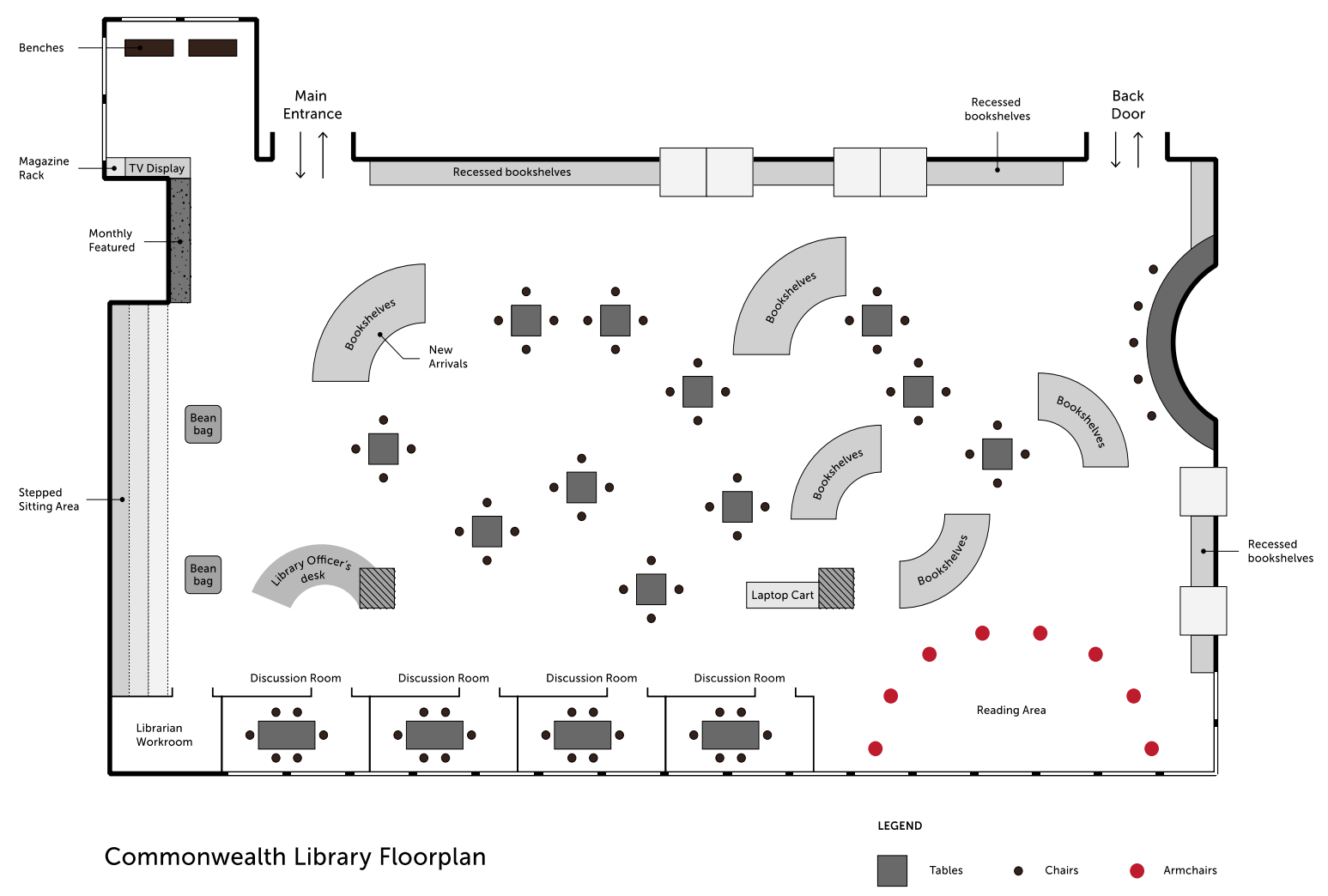

Figure 1. Layout of Commonwealth Secondary School Library

The library adopted an open, contemporary layout design. It can be divided into the following areas:

1. Performance area: This area features three-stepped levels for students to sit and opens up to a small empty area. The area has several different uses, and is often transformed to suit the occasion. On normal library days, the space is used as a reading space. Beanbags are placed in the empty area to create comfortable seating options for students who are looking for a place to browse / read books. Some students are also observed to sit on the steps to read.

2. Book display: Located close to the entrance of the library, the thematic book display is updated monthly. It is placed prominently and is one of the first things that a visitor to the library will encounter and possibly interact with. Notably, fairy lights are also used in this display area to draw attention to the display itself.

3. Main study area: The bulk of the floor space is occupied by small study tables that seat four library users. The area is loosely demarcated into smaller spaces by the use of moveable shelves and other library furniture. The placement of the tables, shelves and other library furniture is thoughtful and user-centric: multiple users can use these various facilities comfortably without affecting other users. The main study area is also loosely divided by movable shelving arrangements. These shelves are typically used to display new arrivals or large books that do not easily fit into the regular shelving spaces in the wall shelves. 
4. Wall shelving: The bulk of the library's collection is stored in wall shelves and is primarily responsible for creating an open layout in this particular library. The shelves are also attractively designed, and feature many different shelving spaces for the school to adopt retail-inspired shelving techniques.

5. Discussion Pods: Four soundproof discussion pods are built in the library with the intention of facilitating discussion. The pods adopt glass walls which serve dual purpose. Students holding discussion inside these pods can use the surface to jot down notes from their discussion. The transparent walls also allow the library assistant to monitor student activity within the pods and intervene if undesirable behaviour is spotted.

6. Reading Corner: Towards the rear of the library are eight armchairs arranged in a semi-circle. The chairs are positioned approximately 30 centimeters apart. This ensures that users occupying the space cannot engage in prolonged conversations with each other, and even if they do, they are limited to two participants only. Students have been observed to use this area for quiet, sustained reading.

7. Wall-seating area: There are eight cubby holes carved into the wall shelving area. They are yellow-green in colour and feature a bench and a small writing surface which will comfortable seat 2 students. The cubby hole is well-lit and is quite heavily utilised by students for studying and reading.

8. Bar seating area: A new addition to the library since major renovations were completed, the barseating area is a repurposing of an empty structural pillar that is situated to the rear of the library. This area features a bar-style writing area with five bar stools placed around the pillar. The space is well-received by users and a variety of behaviours - both individual work and collaborative/group behaviours have been observed in the area.

As the school's library committee was constantly evaluating the space and improving on it, additions were made each term and we would monitor the use of these new spaces. For example, taking feedback from teachers and students alike, a new bar height table was added to a previously empty pillar and high stools were placed there in Term 2. The Library Coordinator deliberated whether to place computers there and in the end, decided to leave it as a flexible working space for students (see Figures 2 and 3). The repurposing was done thoughtfully - the styling and choice of furniture kept to the established aesthetic of the space. The new space was well-received by the users and provided a different kind of seating (bar-type seating) to complement the existing choice of seating available in the library. 


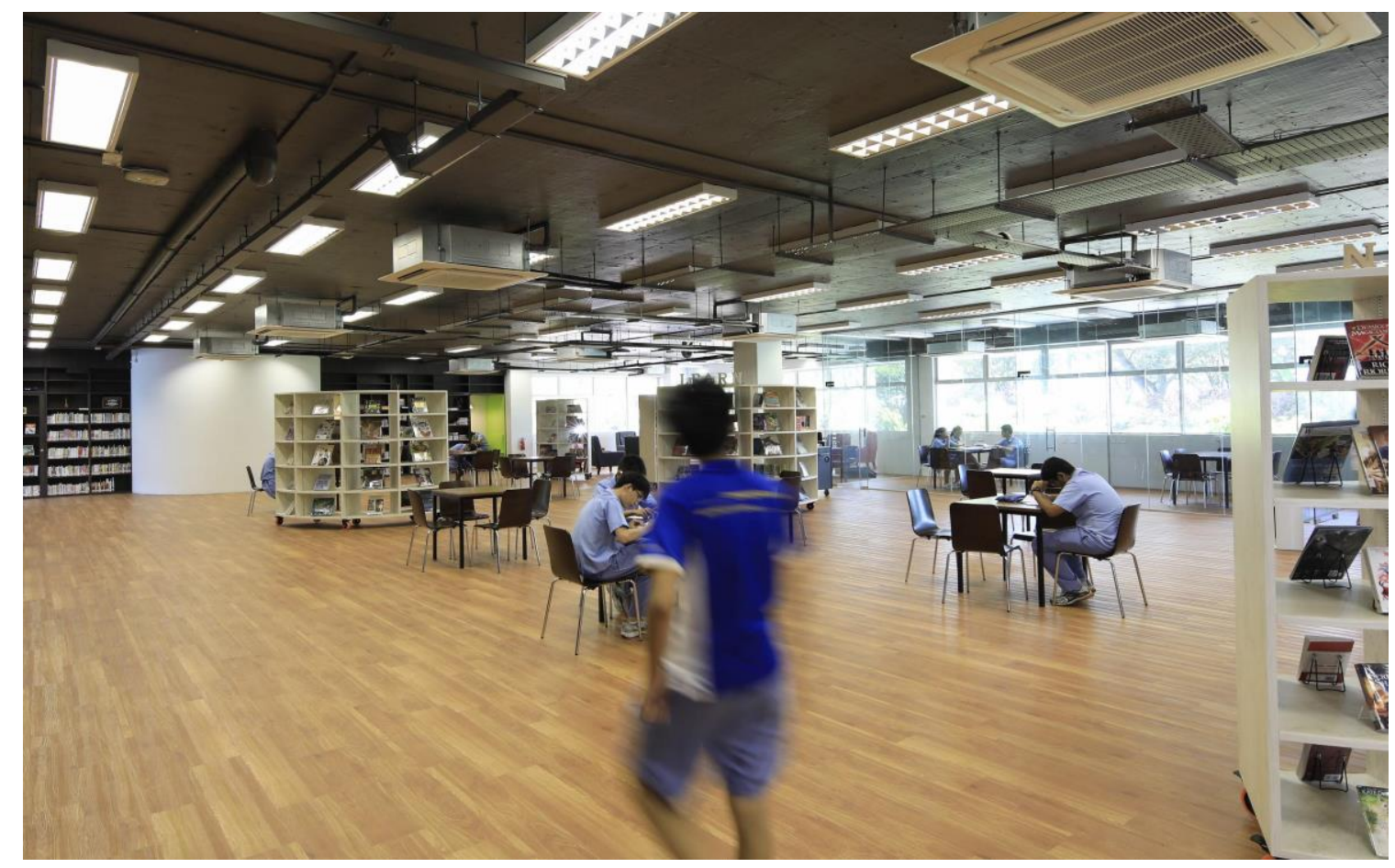

Fig 2. The renovated library, with the structural wall at the end of the room left untouched.

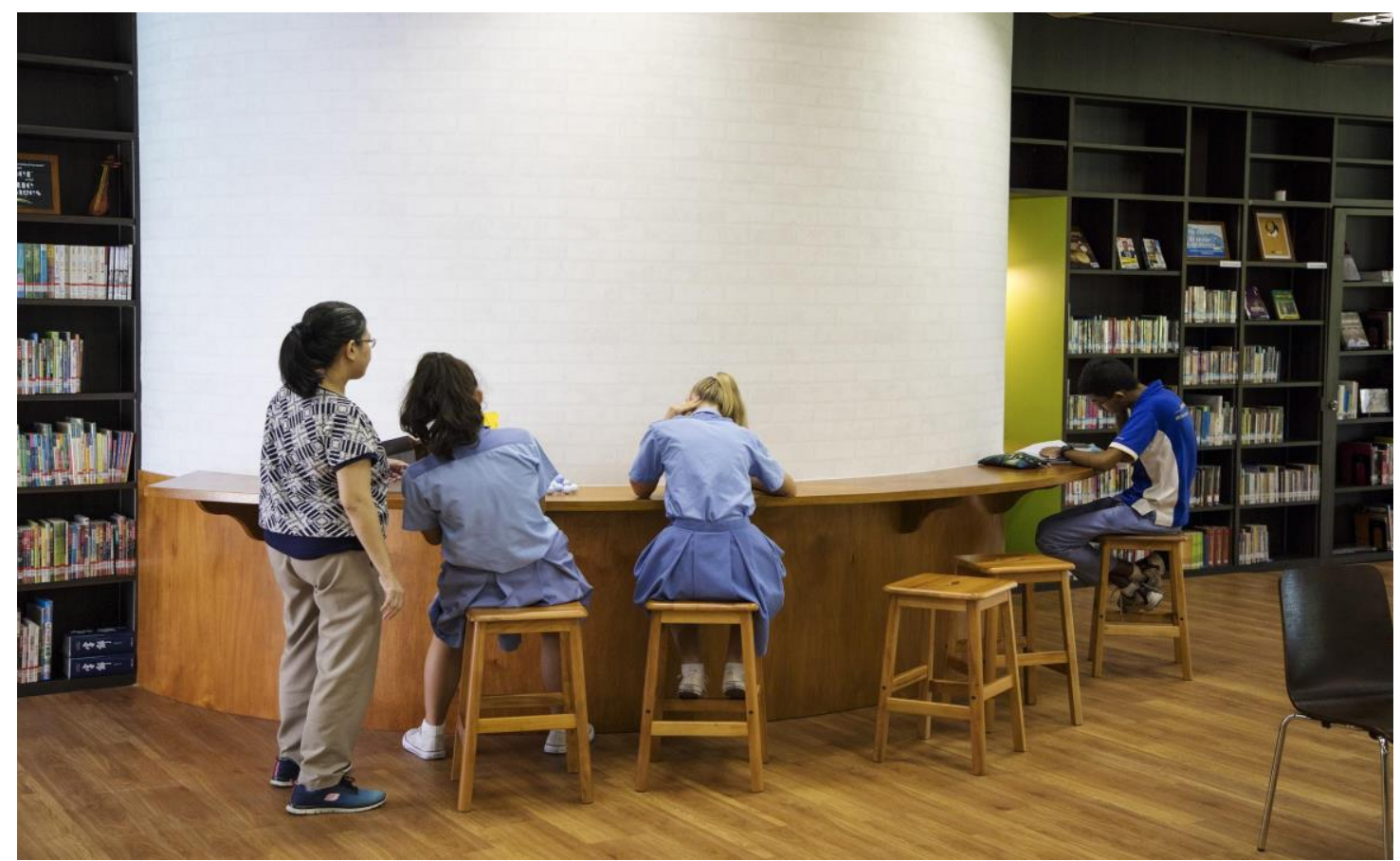

Fig 3. The repurposed wall, completed in Term 2.

\section{Data Collection and Analysis}

The study is a mixed-methods study, pragmatically drawing on both quantitative and qualitative approaches to understand the issue at hand. Data collection was wide-ranging and consisted of a range of tools from a school-wide reading survey, interviews with the Principal, Head of Department and Library coordinators at each school to observation data. 
A school-wide reading survey was administered to students to understand the reading and school library culture in Commonwealth Secondary School. 906 students or $85.7 \%$ of the students responded to the survey. Observation data allowed us to track student behavior and response to space in the library. The researchers visited the library 12 times over nine months (September 2016 to May 2017) to get a sense of how the library space was used over time. Each observation lasted for approximately 8 hours, from the opening to closing of the library. In addition, we would also make a note of special events and turn up to observe the events in the library. In total, we spent 96 hours in formal observations, and eight hours observing special events organized by the school.

Each observation was conducted by two research assistants. One research assistant would conduct time freezes where she would do a count of the number of library users and note the activity conducted within specific spaces in the school library. Counts were made every ten minutes during peak periods (recess breaks and after school) and every twenty minutes during non-peak periods (class time). Activities were broadly coded under the following categories: reading behaviours, study behaviours, collaborative behaviors, research behaviours, leisure behaviors and others. The field notes were further coded to deepen our understanding of each kind of behavior. For example, reading behaviours were further categorized into "sustained reading", "browsing behaviours", "work-related reading", "social reading" and "individual reading".

A second research assistant used duration recordings to capture visual and written "snapshots" of the specific students. The use of photographs allowed us to visualize and illustrate the kinds of behaviors observed in the library. Conversations with students also helped us to understand the motivations behind particular uses of space. We also made use of technology and deployed three Go-Pro cameras in the library to obtain time-lapse data. The Go-Pro camera was programmed to take a snapshot of a fixed location every minute during peak hours. By analysing specific frames, we were able to differentiate the kinds of reading behaviours present in the students. The visual data collected over nine months also allowed us to understand how particular spaces and furniture encouraged certain kinds of behaviours and to see how students colonized the space for their own use.

In addition, fieldwork relating to describing the book collection in the library took place on Jan 25 and April 18, 2017. A summary of the observation included notes on the collection and spatial arrangement. Specific questions guiding the observation are: (1) What are the ways space is used to enhance/ promote the collection? (2) What are best practices that might be adaptable to other collections?

Interviews were conducted with students (including both library and non-library users) to understand how the library was perceived and used. The interviews were transcribed. Field notes and interviews were coded using Nvivo, a qualitative coding software, focusing on how the library was promoted, perceived and utilized as a reading space. Although the project also looked at other aspects of library use such as collaboration, study, research and making, this paper focuses selectively on the data related to the library as a reading space to illustrate how school libraries can encourage or impede the building of a reading culture.

\section{CREATING A READING LIBRARY}

Evidence from various sources showed that the school library had been effective in promoting itself as a space for reading. Firstly, 71.6 of students stated in the reading survey that they visited the school library. Of these students, $30.5 \%$ of the students were regular visitors who visited the library at least once a week. In addition, reading and borrowing ranked among the top three activities students preferred to engage in. Lower secondary students were more likely to read and borrow books whereas upper secondary students spent more time studying and reading, probably because of their preparation for the national high-stakes examination. The popularity of the library is striking in comparison to an earlier study by Loh (2015) where students in another Singapore secondary school did not like to visit their school library and seldom visited their school library.

The data also stands out in comparison to the study from five contrasting schools. While the borrowing rate had decreased in four out of six schools, borrowing was on an upward trend at Commonwealth Secondary School. Figure 5 shows the increased loan rates from January to March, with a 
lesser increase in April, probably due to students' borrowing less to prepare for their mid-year examinations. The increased loan rate is striking because of the library's small collection of 3.5 books per student (as of January 2017). The Library Committee had decided to revamp the library's collection as part of the renovation, and had condemned many of the older collection. The refreshed collection consisted of many new and exciting titles but was substantially smaller as time was required to build up the collection again.

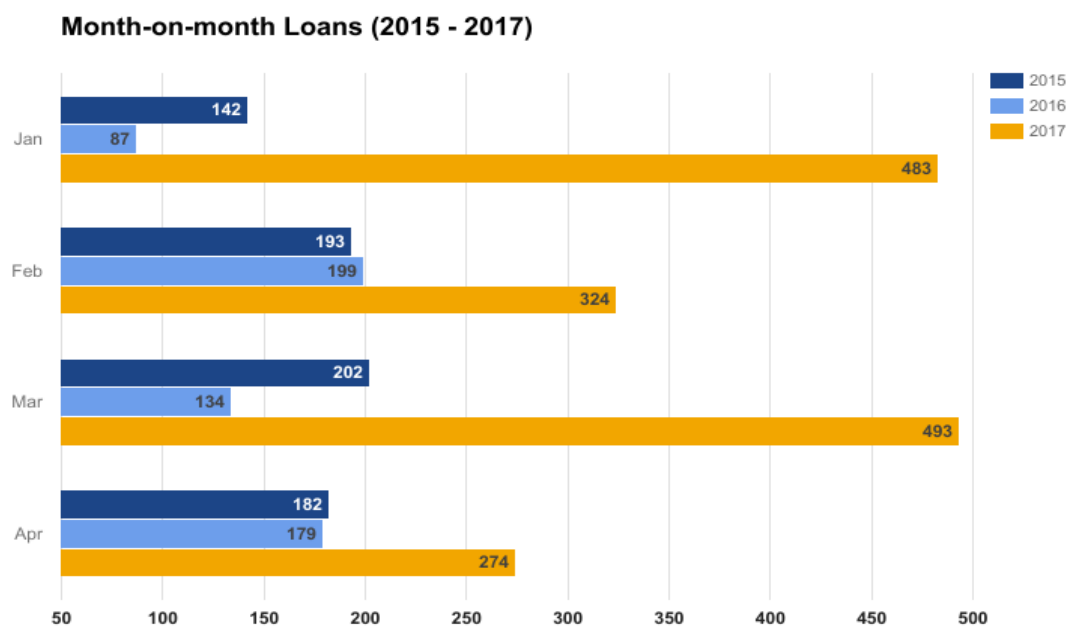

Fig 4. Month-on-month Loans from January to April 2015, 2016 and 2017.

Part of the research involved full-day observations where researchers would document the actual activity in the library to quantify the kinds of activity taking place. The time freezes also demonstrated that students read in the school library (Figure 7). In comparison to the data from five other schools where reading behaviours were observed to happen between $2 \%$ to $7 \%$ of the time, reading was observed to constitute $27.2 \%$ of the time. While studying behaviours (such as completing homework and revision) formed the majority of the observed activities, reading came in second, indicating that by and large, students did use the revamped space and refreshed library collection to read. 


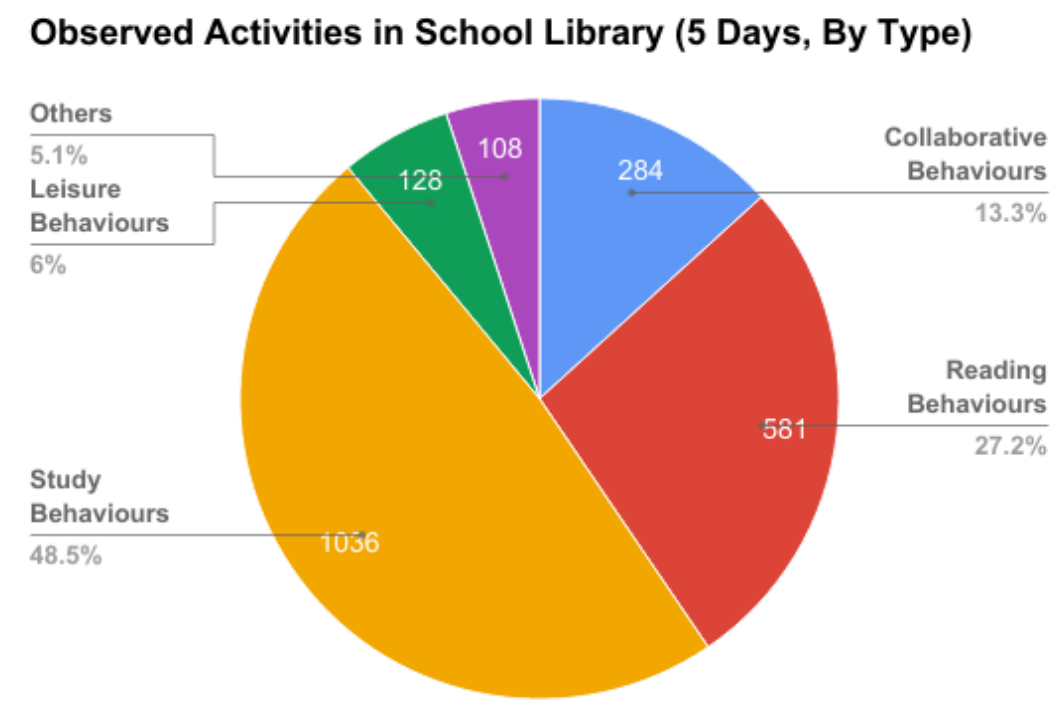

Fig 5. Breakdown of Observed Activities in Commonwealth Library in Term 1.

The following section discusses the various factors that contributed to the school's success as a reading library.

\section{Curating the Selection for Readers}

School libraries can motivate students to read by providing a wide variety of books for students to choose from, including magazines and comics (Adkins and Brendler, 2015) and popular literature (Constantino, 2008; Friese, 2008). A wide range of literature is important for appealing to the different interests of different readers, including avid, reluctant and struggling readers. The increased book loans demonstrate that it is not only the size of a collection that matters. Students' perception about the kinds of books and the environment for reading contribute to their desire to visit the library to borrow books or to read.

Interestingly, students' qualitative feedback on the library focused on the comfortable and quiet environment for studying and reading as well as the well-curated selection of books. Students' comments centred around the perception that there were a wide variety of interesting books, including books that seem unusual and attractive to the students. Qualitative feedback about books include the following:

It is quiet and has a wide choice of books.

The library has lots of books for me to read.

It is big and has rare books I can't find in other libraries.

Nice layout and facilities, many interesting books from a wide range.

It is very calming and has many books I am interested in.

It has many books I have never seen before.

It is big and nice and new books are coming to the collection.

Their comments showed how the selection and advertisement of books made the library seem interesting and unusual, catering to the needs of the students to access a wide variety of books.

The choice of books is driven by the school's expansive view of reading, to encourage any form of reading, whether through magazines, comics, biographies, or inspirational non-fiction. The principal shared that the main purpose of the library should be to inspire "a love for reading and the principle explained that the books in the library should inspire curiosity so that the student would want to "pull the book out" and "pick up the books to read". The Head of the Library Committee personally oversaw the curation of the books for the library, driven by the school's goals to attract students to read, through the 
selection of books that would appeal to the students. The Head was also concerned that students would be exposed to quality literature and that students would read above their reading level.

Notable strategies include a large selection of comics and graphic novels, non-fiction and other large information texts chosen to inspire, and pop-up books that were especially popular with all the students. The selection of "easy" pop-up books about classics (such as Jane Austen and Shakespearean titles) were placed next to the original texts, and worked as a strategy to interest students in reading the pop-up books and even the originals. The perception that the books in the library were current and relevant led to students' reading as a default activity. Students were observed picking up books and magazines during their rest from studying, and would drop by the library when they had some time to browse, read and relax.

\section{Using Retail Principles for Book Choice and Displays}

The increased book rate demonstrates that the size of the book collection may be less relevant than the kinds of books in the selection and the display strategies used to attract the students attention. Advertising books and making them visible is an important strategy to draw students into the library (Makatche and Oberlin, 2011). The school library advertised books physically and online, through Instagram and Twitter.

Physically, the library space could be divided into the entrance or the welcome area, the fixed shelves and the mobile displays, each serving complementary and slightly different functions. The welcome area consists primarily of a digital sign, a monthly thematic display and the multi-use benchers and beanbags. This area is visible through the double-glass front doors and was designed to invite students walking past into the library. Thematic displays seen during the nine months of observation included Romance, Science Fiction and Fantasy. New books were also featured, and were also promoted on Twitter and Instagram.

Taking a leaf from retail principles, attractive and current book displays and display of readers' blurbs are ways to entice students to pick up books. Displaying books with the covers front-facing rather than spine in may take up more space but can encourage greater interest in selecting these titles. Books were arranged by genre rather than Dewey Decimal system, partly due to the limited size of the collection and partly to facilitate ease of browsing and selection. The genres included fantasy, romance, science fiction, graphic novels, travel. Each section was designed attractively. For example, in one of the sections titled "Discover", there are three components: science fiction, historical fiction, and graphic novels. The title suggests new worlds that students can explore and include classics as well as more contemporary books belonging to these genres. Attractive posters and artwork by students (book cover designs or paintings of scenes from books) were displayed to complement the books and to create a sense of excitement about books. These displays were especially attractive as they sat alone on the shelves (no books on either side) and were effective by drawing attention to a particular part of the collection.

Selection and display principles were also guided by the knowledge that less proficient readers may need more encouragement to read. Hence, the attention to attractive book covers were designed to draw the attention of more visual students. Pop-up books were tactile, sparked students' interest and were displayed prominently. Students were observed heading towards the pop-ups, sitting down and eagerly discussing and preparing them. The books in the mobile display shelves tended to serve the purpose of drawing students to pick up books to browse and could be said to fall under the category of "inspirational" texts. These mobile displays give a sense of movement to the entire space; the library is a fluid, changing collection which appeals to its readers.

\section{CREATING PROGRAMMES TO EXCITE READERS AND NON-READERS}

In Reading beyond the book, Fuller and Sedo (2013) note that viewing reading as entertainment, as a "media experience" (p. 248) allows us to understand reading as a social activity that can be shared by many. Understanding that reading includes more than the image of the solitary reader immersed in a book in a lone corner (Long, 1986) helps us understand the need to create excitement around reading to attract students, particularly non-readers (whether reluctant or struggling). 
The Library Committee envisioned the library as a social space for activities around reading and other forms of learning. At the level of programming, the committee aimed to create a vibrant social life around books and reading. Teachers were invited to give book talks and musical performances were held in the library. Each term, there would be a special workshop sponsored by the school and limited to the first 20 participants. The exclusivity of such events created a sense of excitement and buzz around the events in the library. The use of social media to promote books and events also worked to encourage students to be aware of what was happening in the library; students did come into the library to ask for books advertised on Instagram and Twitter.

The library was not just a space that was visited by students. Teachers also began to see the library as an alternative space for activities. During our nine months, we observed English teachers bringing their students in for poetry presentations and reading projects and History teachers bringing their students in for discussion. As the library became an exciting place for teachers to try out different kinds of lessons and teaching, it also became an exciting alternative space for students.

\section{DESIGNING CONDUCIVE SPACES FOR READING}

The use of space and the various displays in the library give an impression of a library that is welcoming, interesting and fun. The sense of place or the students' subjective understanding of the library as place (Cross, 2001) seemed to be that it was a cool and hip place to be at. In the qualitative portion of the survey where students were asked what they liked about the survey, the environment provided emerged as the top reason why students liked their new library. Words such as "quiet", "nice", "comfortable", "relaxing", "cool", "cozy", "beautiful" and "conducive" populate students" responses to the library.

This sense of place was deliberately designed with the Library team describing their objective of making the library a "hip" and "cool" place for students. Firstly, the aesthetics of the renovated library, with special cubby holes for studying and different furniture for different learners was attractive to the students. Balanced lighting, soft music and aromatherapy contributed to the peaceful and calm atmosphere in the library. In our observations, we seldom observe students raising their voices or disrupting others using the space. The way the library was designed and set up encouraged students to adjust their behavior when entering into this space. At the same time, they were permitted to engage in noisy activity when there were events in the library. Students were socialized by their teachers to behave in a particular way in the library but the set up of the library also encouraged these forms of considerate behavior.

Space must correlate to intent for the use of the space. Since the school wanted to encourage reading through the school library, there was deliberate attempt to ensure multiple and varied kinds of spaces for reading. The armchair area situated beside the windows looking out to greenery and the car park space provided students interested in browsing or sustained reading with a comfortable spot to locate themselves. The beanbags and steps at the performance area provided additional seating. Students also colonized the study spaces for reading. In our observations, we have several instances of students moving from one location to another to vary their reading space and posture.

The two screen captures from the time-lapse (Fig. 6) demonstrates how the reading space is wellutilized by students for reading. It illustrates a principle of design of reading spaces learnt from our research. To encourage sustained silent reading, spaces for individual rather than social engagement must be created. Here, the hardback armchairs spaced wide apart allow students who want to read to engage in solitary reading. At the same time, the placement of two movable shelves with attractive books behind the armchairs allowed students to sit down and browse. 

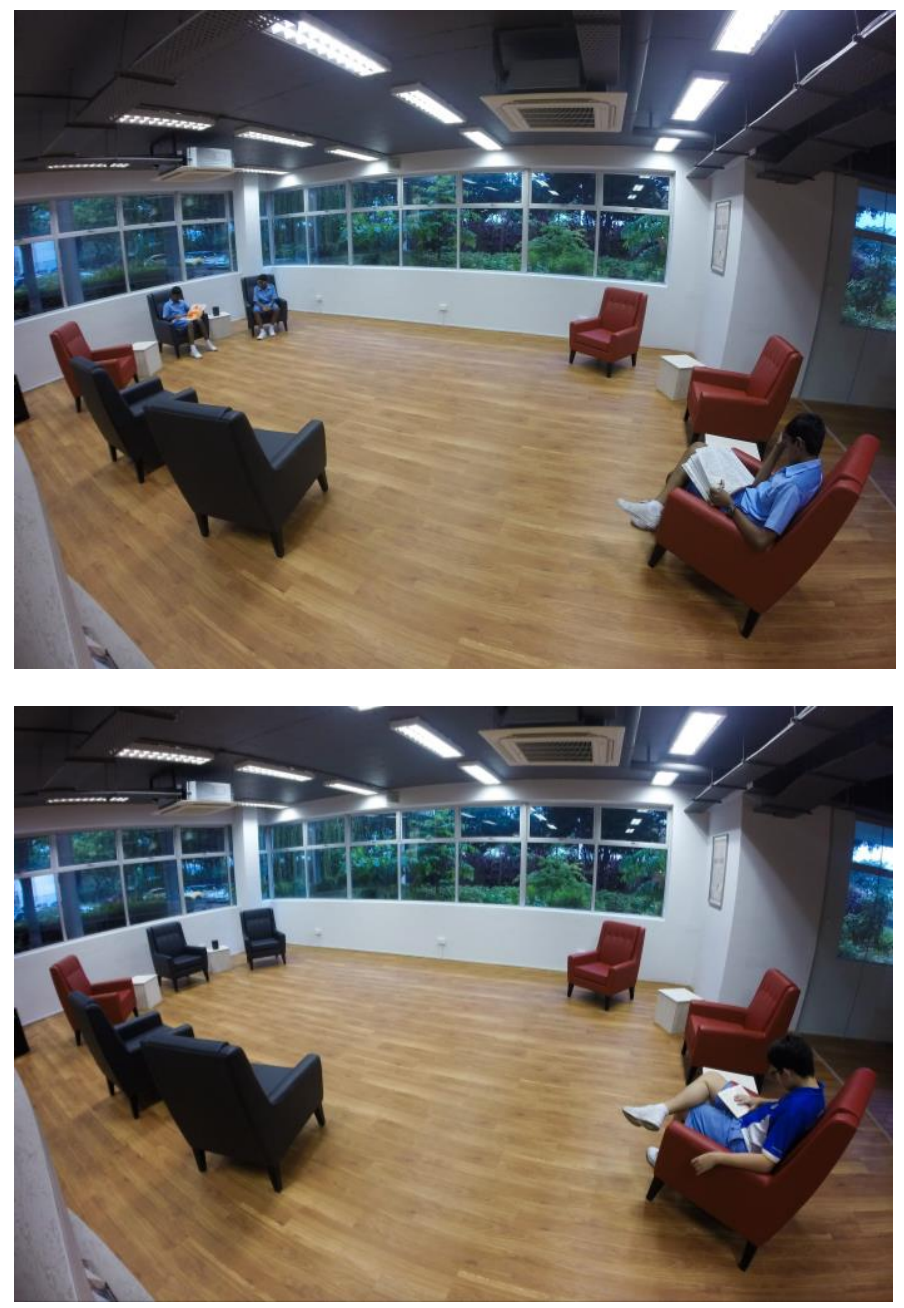

The sequence of two images you see towards the left hand side is part of a time lapse captured in January 2017, from 10:04 to $11: 49$, between the lower and upper secondary recesses.

\section{From top to bottom}

1. Book Browsing: The two boys towards the far left corner in Image 1 are simply browsing the books they have on hand. They leave the observation frame after 2 minutes at 10:22. The boy closer to the right hand side of the frame stays within frame for over 16 minutes, from $10: 16$ to $10: 31$, engaging in sustained reading.

2. Sustained Reading: The boy in the final frames stays in the observed area for 44 minutes, entering at 10:52 and exiting at 11:36, reading Catcher in the Rye by J. D. Salinger over a few days.

Figure 7. Time-Lapse showing different reading behaviours within the Reading Area.

\section{Building an Ecology for Reading}

To build a reading culture, there needs to be an ecology of reading within the school with the principal leading the way (Francois, 2015). The emphasis on reading in Commonwealth was definitely driven by the principal, an avid reader himself, and supported by the staff. In an interview with the principal, he noted the importance of instilling the love of reading among students, rather than having them see it as enforced by authorities and as a chore. Part of this vision is the desire to see reading as a practice that arises from the deliberate will among students, to engage in a habit worth pursuing on their own, outside the purview of any structured reading period. In the words of the school leader: "I would rather give (the students) a bit of breathing space...a quiet space so it's no longer a kind of reading period but it's kind of a quiet moment where I want (them) to read something". The principal wanted the library to be a "third place" for students to "hang out" and to encourage reading. He had high expectations of his staff and his students, stating that they "could be reading more". He was an example to his staff, often sending our readings through Twitter to selected staff to encourage them to read to learn more about their content area or to inspire them in life and in work.

The vision of the library as an attractive space for students and as a reading and learning hub was shared by teachers from different departments, as being a key ingredient for success. For example, all Secondary Two students had to complete a Reading Project which was to create a diorama based on a 
book read recently. The building project was in line with the school's Maker Culture and focusing on a fiction text allowed students to engage in a fun project about reading.

The culture of reading seemed embedded into the school. We observed students reading in the morning assembly period before school started and when they were exempted from Physical Education classes. Interestingly, when students were asked if they were forced to read, most told us that they were encourage but not compelled to read. The reading survey showed that $68.9 \%$ of the students enjoyed reading and that most students read for pleasure (e.g., reading is my hobby, I read for enjoyment, I read for relaxation). Students also saw reading as part of their learning.

\section{CONCLUSION}

Across our research at the six different schools for this study, we observed that the school library was often a microcosm of school life, and that the vision and actual usage of the school library was often inspired or limited by the principal's and staff vision of the school library. Here at Commonwealth Secondary School, the library was seen as a central space for encouraging reading. This guided the library renovation, curating of books and implementation of activities that contributed to students' vision and use of the library as a reading library.

To build a successful reading culture through the school library, it is essential to ensure that there is integration of policy, programme and practice. Without support and a coherent vision supported by thoughtful implementation, attempts to build a reading culture may be fragmented and uneven. Attending the curating and display of books, creating programmes and designing spaces within an ecology that supports reading can ensure the centrality of the school library to amplifying the school's reading culture. 


\section{REFERENCES}

Adkins, D., \& Brendler, B. M. (2015). Libraries and reading motivation: A review of the Programme for International Student Assessment reading results. IFLA journal, 41(2), 129-139.

Allington, R. (1984). Content, coverage, and contextual reading in reading groups. Journal of Reading Behavior, 16(2), 85-96.

Anderson, R., Wilson, P., \& Fielding, L. (1988). Growth in reading and how children spend their time outside of school. Reading Research Quarterly, 23, 285-303.

Barrett, L. (2010). Effective school libraries: evidence of impact on student achievement. The School Librarian, 58(3), 136-139.

Barker, R. G. (1968). Ecological pyschology. Stanford, CA: Stanford University Press.

Bland, D, Hughes, H., \& Willis, J. (2013). Reimagining learning spaces: Final report to the Queensland Centre for Social Science Innovation. Melbourne: Queensland University of Technology.

Cleveland, B. (2017) The school library as a behaviour setting: Exploring the physical and social components behind 'effective learning environments'. In C. Loh (ed.), Building a reading culture roundtable: school libraries and design. Singapore: Commonwealth Secondary School.

Constantino, R. (2008). It's not rocket science - Students know what is good for them: The efficacy of a quality school library. Knowledge Quest, 36(4), 60-63.

Cross, J. (2001) What is sense of place. Headwaters Conference, Western State College, Gunnison, CO, Nov. 2-4,

Cunningham, A., \& Stanovich, K. (1998). What reading does for the mind. American Educator, 1-8.

Francois, C. (2015). An urban school shapes young adolescents' motivation to read. Voices from the Middle, 23(1), 68-72.

Friese, E. (2008) Popular culture in the school library: Enhancing literacies traditional and new. School Libraries Worldwide. 14(2), 68-82.

Fuller, D., \& Sedo, D. (2013). Reading beyond the book: The social practices of contemporary literary culture. New York, NY: Routledge.

Gambrell, L. (2013). Reading motivational engagement: research trends and future directions. In P. Dunston, S. Fullerton, C. Bates et al. (eds.), 62nd Yearbook of the Literacy Research Association. Altamonte Springs, FL, 43-52.

Getrost, C., \& Lance K. (2014). A collaborative success. Voice of Youth Advocates, 37, 28-29.

Grosvenor, I., \& Burke, C. (2008). School. London: Reaktion Books.

IDEO. (2017). Design thinking for educators. Retrieved May 17, 2017 from https://www.ideo.com/post/design-thinking-for-educators,

IFLA School Libraries Section Standing Committee. (2015). IFLA school library guidelines (2nd rev. ed.). The Hague, Netherlands: International Federation of Library Associations and Institutions.

Ivey, G., \& Broaddus, K. (2001). "Just plain reading": A survey of what makes students want to read in middle school classrooms. Reading Research Quarterly, 36(4), 350-377.

Kirsch, I., de Jong, J., Lafontaine, D., et al. (2002). Reading for change: Performance and engagement across countries. Paris, France: Organisation for Economic Co-operation and Development.

Krashen, S. (2004). The power of reading: Insights from research, Portsmouth, NH: Heinemann.

Lance, K. (2002). What research tells us about the importance of school libraries. Knowledge Quest, 31, 17-22.

Lefebvre, H. (1991). The production of space, Cambridge, MA: Blackwell.

Loh, C. E. (2015). Building a reading culture in a Singapore school: identifying spaces for change through a socio-spatial approach. Changing English, 22(2), 209-221.

Long, E. (1986). Women, reading, and cultural authority: Some implications of the audience perspective in cultural studies. American Quarterly, 38(4), 591-612.

Lu, Y-L., \& Gordon, C. (2007). Reading takes you places: A study of a web-based summer reading programme. School Library Media Research 10.

Makatche, K., \& Oberlin, J. U. (2011). Building a culture of reading. School Library Monthly, 28(3), 1214. 
Neuman, S. B., \& Celano, D. C. (2012). Worlds apart: One city, two libraries, and ten years of watching inequality grow. American Educator, 36(3), 13-23.

Parrott, D., \& Keith, K. (2015) Three heads are better than one: Librarians, reading specialists, and classroom teachers in the learning commons. Teacher Librarian, 42(5), 12-18.

Jay, S., \& Wu, S. Y. C. (2001). How the amount of time spent on independent reading affects reading achievement: A response to the National Reading Panel. Minneapolis, MN: University of Minnesota.

Shilling, C., \& Cousins, F. (1990). Social use of the school library: The colonisation and regulation of educational space. British Journal of Sociology of Education, 11(4), 411-430.

Stanovich, K. (1986). Matthew effects in reading: Some consequences of individual differences in the acqusition of literacy. Reading Research Quarterly, 22, 306-407.

Todd, R. J., \& Kuhlthau, C. C. (2005). Student learning through Ohio school libraries, Part 1: How effective school libraries help students. School Libraries Worldwide, 11(1), 63-88.

Ujiie, J., \& Krashen, S. D. (1996). Comic book reading, reading enjoyment, and pleasure reading among middle class and Chapter I middle school students. Reading Improvement, 33, 51-54.

Wigfield, A., \& Guthrie, J. T. (1997). Relations of children's motivation for reading to the amount and breadth or their reading. Journal of Educational Psychology, 89(3), 420-432.

\section{Acknowledgements}

This work was supported by the National Institute of Education under OER5/16 LCE Building a Reading Culture: A Nationwide Study of Reading and School Libraries in Singapore Secondary Schools. More about the project can be found on the project website: www.readingculturesg.org. 